\title{
CORE VALUES ORGANIZATIONAL CHANGE
}


This page is intentionally left blank 


\section{CORE VALUES}

.

\section{ORGANIZATIONAL \\ CHANGE Theory and practice}

\section{Alma Whiteley Jervis Whiteley}

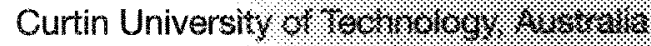

\section{World Scientific}




\title{
Published by
}

World Scientific Publishing Co. Pte. Ltd.

5 Toh Tuck Link, Singapore 596224

USA office: 27 Warren Street, Suite 401-402, Hackensack, NJ 07601

UK office: 57 Shelton Street, Covent Garden, London WC2H 9 HE

\author{
Library of Congress Cataloging-in-Publication Data \\ Whiteley, Alma M. \\ Core values and organizational change : theory and practice / Alma Whiteley and Jervis \\ Whiteley. \\ p. cm. \\ Includes bibliographical references and index. \\ ISBN 13 978-981-256-902-8 -- ISBN 10 981-256-902-2 \\ ISBN 13 978-981-256-903-5 (pbk) -- ISBN 10 981-256-903-0 (pbk) \\ 1. Corporate culture. 2. Organizational change. I. Whiteley, Jervis.
}

HD58.7.W497 2007

$658.4^{\prime} 06--d c 22$

2006041372

\section{British Library Cataloguing-in-Publication Data}

A catalogue record for this book is available from the British Library.

Copyright 12007 by World Scientific Publishing Co. Pte. Ltd.

All rights reserved. This book, or parts thereof, may not be reproduced in any form or by any means, electronic or mechanical, including photocopying, recording or any information storage and retrieval system now known or to be invented, without written permission from the Publisher.

For photocopying of material in this volume, please pay a copying fee through the Copyright Clearance Center, Inc., 222 Rosewood Drive, Danvers, MA 01923, USA. In this case permission to photocopy is not required from the publisher.

Typeset by Stallion Press

Email: enquiries@stallionpress.com 


\section{DEDICATION}

There is always a wellspring that fuels the hard work and creative thinking to write a book. Our joy and inspiration came from our family.

Elaine, David and Heather for your values, courage and caring.

Lucinda, Bryony and Anni for loyalty and letting us know who we are.

For our grandchildren who keep us young. 
This page is intentionally left blank 


\section{ACKNOWLEDGMENTS}

We are representatives of the employees and managers who so generously shared their experiences with us. We hope that their wisdom shines throughout this book. To our friends at ALSCO, a thank you for an exciting partnership and your stimulating contributions.

'There's nowt more practical than theory, lads'.

(an old Yorkshire proverb) 
This page is intentionally left blank 


\title{
PREFACE
}

\begin{abstract}
But as Adam Kahane says, most change processes are superficial because they don't generate the depth of understanding and commitment that is required for sustaining change in truly demanding circumstances ... when you're facing very difficult issues or dilemmas, when very different people need to align in very complex settings and when the future might be very different from the past, a different process is needed... We have come to call these [ideas on process] sensing, presencing and realizing. (Senge et al., 2005, p. 87)
\end{abstract}

We wrote this book as an 'informed story'. We wander through our thoughts about the nature of work and the true (in a philosophical sense) nature of humans in organizations. We bring to you ideas from the employees and managers who have educated us and the theorists whose knowledge we gratefully acknowledge. We tell the story of how we felt a little unsatisfied with management and organizational behavior texts that began with a 'this is how it is' history of organizational theory. We asked ourselves. "How did things come to be this way?" Could organizations have been any different to the impersonal and objective overlay represented by outcomes-based methodologies? In particular, we were impressed by the contrast between the highly emotive worlds we inhabited in our own organizations and the assumptions of logical and rational worlds embedded in the many structures, systems and processes that characterize contemporary organizational life. There is a great temptation when writing a book to follow the logical and rational path and obey the convention of "not jumping all over the place". To be true to the idea of emergence and spontaneity that represent the real world of dialogue, we invite you to join with us as active readers and bring your own order to the book. 
As relative newcomers to the academic world (we had been in the workplace for years before this), we were struck by the characteristics of many management and organizational behavior texts. First, they did not seem to start from any sort of philosophical explanation, which would indicate where the authors were coming from regarding their thoughts about the 'true' nature of the human being in the organization. Secondly, texts typically began with a historical account of the various theories that evolved since around the time of the industrial revolution in the 19th century in England and the United States. These accounts were very helpful for informing managers about the history of management theory, but where do they lead?

However, to us, there was a taken-for-grantedness about history. Not too many attempts were made to critically discuss why things came to be this way. A notable exception was the paper by Barley and Kunda (1992), who presented an excellent and critical account of the waves of ideologies in management history. Not only were descriptive accounts of management history given in management texts, but we noticed that there was an overwhelming portrayal of the rational and logical side of people and organizations. This was evident in descriptions of the various functions almost all organizations seemed to share.

An example is the recruitment and selection process. Job applications were designed to elicit such factual data as level of education, years of experience, technical skills, and professional qualifications. This information was transformed into a match with the various duties and responsibilities required by job or role descriptions. These descriptions were typically broken down into discrete activities, factually expressed. In turn, these were circumscribed by rules, regulations and procedures. So here we see the sort of match that is very prevalent in organizations, that is the match between a person's evidence-based qualities and those of the job or task to be performed. We have not seen too many examples of values-based recruitment and selection.

As every project manager knows, organizations are complicated and complex. Complicated means that you can write specifications, procedures and even rules to control the sequence of events to follow. Complex means that the plan itself is always renegotiating the right outcome, the right way to go about it and what is success. This is true of all large material projects, such as building a power station. And it is also true for managing change within an organization of any size. Why? Because in both cases it is the interaction between people that makes things happen but is at the same time the locus of 
uncertainty and risk. Our book uses complexity theory to help you understand how to develop the core values in your organization, which will lead towards stability, cooperation and teamwork.

This book has been in the making for 10 years because Alma wanted to demonstrate that the core values approach works in practice. That is exactly what we do in the ALSCO case study in Chapter 11. Alma's story actually started long before that and found its way into print with Managing Change: A Core Values Approach (Whiteley, 1995). In the preface to that book Alma recounted her experience as a young adult on the dockside of Newcastle-uponTyne in the 1950 s.

\begin{abstract}
Around two hundred technicians, labourers and workers stood before a shipyard foreman who 'recruited' labour from his 'office', a wooden crate, upon which he raised himself from the crowd. He importantly pointed first to one person and then another, signifying selection for work. He was, you may say, breaking the rules of human respect and dignity, not out of malice but because in those days this was the way things were done. This was the labour market. The feelings of violation of the human condition embedded in that early experience gave me the determination to make sense of the situation.
\end{abstract}

For several years in her early career, working at a government department matching labor to jobs, Alma was lucky enough to visit many organizations, talking to employees, supervisors and managers ostensibly about labor turnover but as it turned out, about life at work. She was to hear many voices over the years and some of the most poignant were from youth trainees whom she worked with for her doctoral research about so-called 'low achievers' (Whiteley, 1987).

Gibson Burrell (2003), in his comment on the future of organizational theory, suggested that there is an important new question "For whom do we write?" This has posed something of a difficulty for us. It seems easier to identify for whom we do not specifically write, although one never knows what is of interest to others.

Although strategy formulation is an important part of managing change, the voices we bring to this book are not those of members of the Board of Directors. It is not until we describe ideas on 'third wave change' in Chapter 6 that we begin to include senior managers in the change dialogue. Having said 
this, the active support of members of the senior management group is essential to the success of the core values method. Also, it tends to be senior managers who hear about the book and go on to use it in the organization. We believe that managers (and here we include supervisors, forepersons, and the various administrative titles given to those whose job is to work through others) are our target audience for actually reading the book. We say this because typically, employees prefer to communicate through conversations, stories and as brief analyses of formal literature as possible. However, Alma was inspired by the voices of employees. They first alerted her to the gap between what managers assumed employees valued from them and what they actually valued. They also set her thinking about their values as benchmarks for beliefs and behaviors. In short, it is employees who have 'written' much of the core values approach and method, leaving it to us to be as faithful as possible to their sentiments and wisdom.

This is a big responsibility as the fruits of many conversations and confidences have to be portrayed within the inhospitable medium of the written word. Initially, this book will reside within the domain of management education. This means that the conversation of the book will be supported by ideas and theories of people who are very different to the employees who provide the central core of knowledge in the book. One mechanism used in this book is the pronoun 'we' to describe experiences and ideas. Responsibility for all that is written is taken by the authors, but 'we' is also used to denote the contributions of employees, managers and theorists. 


\section{CONTENTS}

Dedication $\quad$ v

Acknowledgments vii

$\begin{array}{ll}\text { Preface } & \text { ix }\end{array}$

Part 1 The Genealogy of Change 1

1 Introduction 3

1.1 The "True' Nature of Work and People . . . . . . . . . . . . 9

1.2 Synopsis of Chapters . . . . . . . . . . . . . . 16

1.3 Questions for Discussion . . . . . . . . . . . . 20

2 Philosophy and Business Management 22

2.1 The Origins of Philosophical Thinking . . . . . . . . . . 23

2.2 Aristotle's Legacy to Management . . . . . . . . . . . . . . 29

2.3 The Contemporary Relevance of Philosophy . . . . . . . . . 35

2.4 Philosophy and the Theory of Organizing . . . . . . . . . . 40

2.5 Questions for Discussion . . . . . . . . . . . . . 43

3 Modernism, Status Quo Thinking and Postmodernism 45

3.1 Modernism . . . . . . . . . . . . . . . . . 45

3.2 The Modernist Organization . . . . . . . . . . 50

3.3 Taylorism . . . . . . . . . . . . . . . 55

3.4 Structures, Functions and the Status Quo Thinking . . . . . 59

3.5 Institutionalism and the Informal Organization $\ldots \ldots \ldots 6$ 
3.6 After Modernism . . . . . . . . . . . . . . . . . . . . 69

3.7 Postmodernism and the Social Sciences . . . . . . . . . . 71

3.8 The Postmodern in Management . . . . . . . . . . . . . . 73

3.9 Questions for Discussion . . . . . . . . . . . 83

4 Spirit and Soul $\quad 84$

4.1 Change and Employee Power . . . . . . . . . . . . . . 85

4.2 Boundaries and Fragmentation . . . . . . . . . . . . 90

4.3 Human Givens . . . . . . . . . . . . . . . . . . . . . 91

4.4 Stress Through Change . . . . . . . . . . . . . . . . 94

4.5 Stories of Spirit and Soul in the Workplace . . . . . . . . . 95

4.6 Handling Emotions . . . . . . . . . . . . . . 102

4.7 Core Values and Emotions . . . . . . . . . . . . . . 107

4.8 Questions for Discussion . . . . . . . . . . . . . . . . 109

5 Complexity Theory and Managing Change 110

5.1 Thinking Complexity-The Foundations . . . . . . . . 112

5.2 Complexity: An Alternative Way of Thinking . . . . . . . . 114

5.3 Complexity Concepts and Their Values . . . . . . . . . . 118

5.4 Applying Complexity to Organizations . . . . . . . . . . . . 141

5.5 Questions for Discussion . . . . . . . . . . . . . . . 143

Part 2 The Theory and Practice of Change 145

6 What is Change? A New Model of Change 147

6.1 Reflections on Change . . . . . . . . . . . . . . . 147

6.2 The Rational Economic Model of Change . . . . . . . . . . . 151

6.3 The Social Relational Model of Change . . . . . . . . . . 157

6.4 The Duality and Quantum Thinking Model of Change . . . . 163

6.5 Organizational Behavior Theory and Third Wave Change . . . 166

6.6 Duality and the Space of the Adjacent Possible (SAP) . . . . 168

6.7 Questions for Discussion . . . . . . . . . . . . . . . 174

7 The Core Values Model 175

7.1 Values . . . . . . . . . . . . . . . . 175

7.2 Organizational Culture . . . . . . . . . . . 178 
7.3 The Core Values Model . . . . . . . . . . . . . . . . 182

7.4 Rational and Social Building Blocks of the Organization . . . . 185

7.5 The PATOP Diagnostic Model . . . . . . . . . . . . . . 193

7.6 Strategy Without Core Values . . . . . . . . . . . . 196

7.7 Action Research: The Core Values Method . . . . . . . . . . . 202

7.8 Questions for Discussion . . . . . . . . . . . . 203

8 The Core Values Method 205

8.1 Setting the Scene . . . . . . . . . . . . . 205

8.2 Employee as Internal Customer . . . . . . . . . . . 207

8.3 The Employee Participation Model . . . . . . . . . . . . 210

8.4 Role of the Manager in Preparing for Change . . . . . . . . 213

8.5 The Core Values Method . . . . . . . . . . . . . . . . 214

8.6 Creating Shared Values . . . . . . . . . . . . . . . 218

8.7 Practical Example of the Core Values Method . . . . . . . 220

8.8 Questions for Discussion . . . . . . . . . . . . . 232

Part 3 Implementing Third Wave Change 235

9 Changing Mindsets 237

9.1 The Traditional Mindset . . . . . . . . . . . . . . . 238

9.2 Inclusivity . . . . . . . . . . . . . . . . 240

9.3 Culture as Negotiated Reality . . . . . . . . . . . . 242

9.4 Developing Shared Worlds of Meaning . . . . . . . . . . . 248

9.5 Dialectic and Communication . . . . . . . . . . . 250

9.6 Human Resource Management-A Special Case . . . . . . . . . . 256

9.7 Questions for Discussion . . . . . . . . . . . . . 260

10 Culture-Building and Culture-Binding 262

10.1 Overview . . . . . . . . . . . . . . . . . 262

10.2 Culture-Building and Symbols . . . . . . . . . . . 268

10.3 Matching Organizational Design to Culture-Building . . . . . 276

10.4 Culture-Binding . . . . . . . . . . . . . 283

10.5 Managers as Designers of Rituals . . . . . . . . . . . . . 290

10.6 Questions for Discussion . . . . . . . . . . . . . 291 
11 The ALSCO Case Study - The Core Values Method in Practice

11.1 The Steiner and ALSCO Stories . . . . . . . . . . . 295

11.2 ALSCO and Core Values Meet . . . . . . . . . . . . . 297

11.3 Going into the Change Program . . . . . . . . . . . . . . 299

11.4 The Executive Workshop . . . . . . . . . . . . . 300

11.5 Engineering the Transition . . . . . . . . . . . . 305

11.6 The General Managers' (Branch) Core Values Workshop . . . . 308

11.7 The Victoria Branch Workshop . . . . . . . . . . . . 312

11.8 From Core Values to Behaviors . . . . . . . . . . . . . . . . 319

11.9 Reflections and Reminiscences . . . . . . . . . . . . 322

11.10 Conclusion . . . . . . . . . . . . . . . 327

$\begin{array}{ll}\text { Afterword } & 329\end{array}$

$\begin{array}{ll}\text { References } & 331\end{array}$

Index 339 